\title{
LÍNGUA PORTUGUESA E REALIDADE BRASILEIRA: O DIRETÓRIO DE POMBAL SEGUNDO CELSO CUNHA
}

\author{
Bethania Sampaio Corrêa Mariani
}

RESUMO: Le but de ce travail c'est présenter une analyse de la citation de l'édit du marquis de Pombal dans trois textes écrits par Celso Cunha. On a étudié le processus de réconfiguration de la formation discursive des grammairiens qui dès le XIX siècle ont produit un sens sur la langue qu'on parle au Brésil. On a travaillé avec les réflexions et les concepts théoriques de l'école française de l'analyse du discours.

PALAVRAS-CHAVE: citação, édito, formação discursiva, intertexto, língua brasileira, língua portuguesa.

Todo enunciado, toda seqüência de enunciados é, pois, lingüisticamente descritível como uma série (léxicosintaticamente determinada) de pontos de deriva possíveis, oferecendo lugar à interpretação. É nesse espaço que pretende trabalhar a análise de discurso.

M. Pêcheux

Tradicionalmente a Análise de Discurso toma para si a tarefa de depreender e analisar as constelações de textos constitutivos das práticas discursivas de uma formação social dada. Tomando como fundamental as relações entre linguagem e história, os textos — objeto empírico de análise — são dimensionados enquanto monumentos históricos aglutinadores e produtores de

\footnotetext{
* Língua portuguesa e realidade brasileira é o título de um livro de Celso Cunha publicado em 1975 pela editora Tempo Brasileiro. O presente trabalho integra o projeto A História das Idéias Lingüísticas no Brasil: a construção de um saber metalinguístico e a constituição da língua nacional, coordenado pela profa. Dra. Eni P. Orlandi, UNICAMP.
}

Bethania Sampaio Corrêa Mariani é professora na Universidade Federal Fluminense 
sentidos que, sem possuir origens precisas, circulam de época para época, em um processo perene de retomadas, silenciamentos, confrontos, rupturas e transformações.

A análise da superfície lingüística de um momento textual pode evidenciar os traços de heterogeneidade que constituem a trama discursiva. Isto quer dizer que a construção de um texto supõe, por parte do autor, a possibilidade de alinhavar os sentidos engendrados em diferentes lugares enunciativos e que irrompem na tessitura da formação discursiva à qual o texto em questão está filiado. Um olhar discursivo busca depreender e analisar os mecanismos lingüísticos que, se atestam a heterogeneidade, produzem, por outro lado, efeitos de unidade. Um olhar discursivo quer entender o modo como várias formações discursivas podem estar atravessando um texto, seja porque há enunciadores distintos do locutor, seja porque o locutor se representa no texto em diferentes posições enunciativas filiadas, por sua vez, à rede de formações discursivas constitutivas da história de sua formação social ${ }^{1}$. A questão da posição enunciativa, aliás, é um dos pontos capitais da análise do discurso: não estará em causa aqui indivíduos, sociologicamente caracterizáveis, mas, sim, as relações imaginárias estabelecidas em função e em torno das diversas posições enunciativas que, na forma de palavras, expressões e enunciados, podem ser depreendidas nos textos.

A citação é um mecanismo lingüístico que visivelmente presentifica a heterogeneidade discursiva: por se tratar de um fragmento estranho, produzido em uma outra situação enunciativa, a citação marca uma alteridade, necessitando, assim, ser integrada à trama textual em si e ao fio discursivo. Em outras palavras, interessa a observar o modo como uma citação migra de um texto para integrar uma rede de outros textos que numa época dada constituem as possibilidades do dizer de uma formação discursiva.

Com o presente estudo, objetivo apresentar o percurso de uma citação específica, a qual aparece em três diferentes textos de Celso Cunha. Trata-se de um fragmento do édito promulgado pelo Marquês de Pombal, em 3 de maio de 1757, aplicado inicialmente no Pará e no Maranhão e estendido em 17 de agosto de 1758 para todo o Brasil, citado por Cunha em 1) Linguagem e condição social no Brasil, 1979a, 2) A situação lingüística de Cabo Verde e Guiné-Bissau - Português e Crioulo frente a frente, $1979 \mathrm{~b}$ e 3) A questão da norma culta brasileira, $1985{ }^{2}$

\footnotetext{
${ }^{1}$ Refiro-me aqui à distinção feita por Ducrot (1984) entre locutor e enunciador bem como à noção de autor tal como Orlandi (1988, p.101) e Orlandi e Guimarães (1988, p.53) a apresentam. Na análise feita, a função autor, tal como Orlandi a formula a partir de Foucault, é fundamental. Conforme a autora, "autor é a função que o eu assume enquanto produtor de linguagem, sendo submetido às regras das instituições. [...] Cabe ao autor manejar os diversos enunciadores colocados em cena de forma a dar unidade, coerência e coesão ao texto. É na escola que o aluno aprende o controle dos mecanismos com os quais está lidando quando escreve. Do autor se exige: coerência; respeito aos padrões estabelecidos, tanto quanto à forma do discurso como às formas gramaticais; explicitação, clareza; conhecimento das regras textuais; originalidade; relevância e unidade, não-contradição e progressão do discurso." (id., p.78).

${ }^{2}$ Referências mais específicas podem ser encontradas na bibliografia geral.
}

132 


\section{BREVES OBSERVAÇÕES INICIAIS}

Fato interessante a se destacar de imediato é a existência da repetição integral, entre os artigos citados, de parágrafos inteiros, sobretudo no que diz respeito às causas e às consequiências da implementação do édito no Brasil. Semelhanças e diferenças jogam nos três trabalhos da seguinte maneira: o primeiro está mais voltado para apresentar, justificar e rebater críticas feitas ao projeto NURC; o segundo, publicado pela primeira vez em 1979, um dos quatro estudos presentes no livro Língua, nação e alienação (1981), discute a situação política e pedagógica do português face ao crioulo e faz uma menção ao édito na forma de nota de rodapé; o terceiro, por fim, publicado na Revista de Letras da Universidade do Ceará, foi, originalmente, uma conferência proferida no V Encontro Nacional de Professores Universitários de Literatura Portuguesa. Desde já adianto que há pequenas diferenças na citação do diretório - em termos de pontuação e uso de aspas, sobretudo - em cada um dos artigos. Estas diferenças representam erros de edição, mas não afetam nem alteram a compreensão do édito como um todo. Infelizmente não tive acesso a nenhuma edição fidedigna do édito de Pombal e por este motivo preferi colocar lado a lado, em anexo, as três versões citadas por Cunha.

Ainda em linhas gerais, devo dizer que Celso Cunha não esconde seus propósitos: centrando suas pesquisas no terreno por ele denominado de dialectologia vertical (1985, p.20), lançando mão de fatos históricos e enfatizando a deriva e a diversidade lingüísticas, o autor quer descrever e explicar a situação atual da norma do português culto falado no Brasil, ou norma culta oral (id., p.23).

Para ele, "a variante brasileira da língua portuguesa é o nosso "vulgar ilustre', o falar de nossas cidades, o padrão difundido." (1981, p.131). Nos três estudos citados, Cunha busca sempre correlacionar linguagem e sociedade, argumentando em favor das diferenças entre o português do Brasil e o de Portugal.

Ao buscar uma classificação para o português do Brasil, Cunha rejeita aquelas que supõem conceituações "eivadas de preconceitos historicistas ou nacionalistas." Por este motivo, recusa as denominações língua brasileira, dialeto brasileiro e língua ou idioma nacional: a primeira por ser jacobina, a outra por ser subserviente e a terceira por denominar de forma neutra e anódina a língua falada em um país (1985, p.15).

É a partir do quadro conceitual do lingüista russo G. Stepanov que Cunha classifica "a modalidade que o Português assumiu na América" como "uma variante nacional americana, com uma dualidade ou assimetria de normas, distinta da variante nacional peninsular, cuja norma é relativamente estável". (id., p.64). Para Cunha, a instabilidade da língua culta (sic) no caso brasileiro tem raízes históricas. Diz o autor: "É a história que vai explicar-nos esta relativa unidade da língua culta de Portugal e do Brasil e as sensíveis, por vezes profundas, diferenças da língua popular em áreas dos dois países.”(CUNHA, 1981, p.18). E é neste ponto da argumentação que a referência ao papel desempenhado pelo Marquês de Pombal 
no século XVIII se faz necessária. Após a citação do édito (ou diretório) são elaboradas, em seguida, algumas considerações e conclusões. Segundo Cunha, em função do diretório imposto pela metrópole, a língua portuguesa além de passar a ser obrigatoriamente ensinada nas poucas escolas existentes, torna-se veículo de comunicação obrigatório entre índios, negros e brancos fosse nas lavouras, fosse no comércio, fosse nas interações religiosas. Ainda de acordo com o autor, quarenta anos depois, em 12 de maio de 1798, quando o diretório foi abolido por ordem do governador do Pará, D. Francisco Maurício de Sousa Coutinho, a língua portuguesa já tinha passado a dominar em todo o território nacional - com exceção da Amazônia - não precisando mais ser imposta. Foi o fim da língua geral, antes dominante e falada por índios, negros, mulheres e crianças brancas, bandeirantes e jesuítas.

\section{TEXTUALIDADE E CITAÇÃO}

Por que, antes de mais nada, afirmar a heterogeneidade do texto? A heterogeneidade discursiva é o fato de se encontrar em uma mesma situação enunciativa, mecanismos lingüísticos reveladores de vários lugares enunciativos. Dito de outra maneira, uma mesma enunciação pode conter vozes que integram várias e diferentes práticas discursivas.

A trama da textualidade resulta, em parte, do modo como o autor (enquanto posição, e não, repito, enquanto indivíduo) organiza as várias posições do sujeito, isto é, seu modo de alinhavar a dispersão (diríamos, até, inescapável) dos enunciados dessas várias formações discursivas que se entressilenciam, retomam, e contradizem, enfim, entram em relação umas com as outras no próprio corpo do texto. Pode-se então dizer que a citação corresponde a um dos processos lingüísticos que atestam a heterogeneidade discursiva, uma vez que representa a entrada de um enunciador diferente. A citação representa uma manifestação evidente da heterogeneidade discursiva por dois motivos: 1) ela é marcada, na superfície textual, ou pelo uso de aspas ou por outro recurso gráfico que também a destaque; 2) ao introduzi-la no texto, o autor se posiciona aderindo mais ou menos ao enunciador colocado em cena.

De acordo com Maingueneau, "citar é tirar pane de um material já significante em um discurso para fazê-lo funcionar em um novo sistema significante. Não basta identificar o discurso do qual foi tirada a citação ou estudar a transformação que a citação sofreu. É necessário dar conta de seu estatuto na nova estrutura à qual ela está integrada." (1991, p.136). Ainda segundo o autor, as citações podem ter distintas funções no discurso. Ele destaca cinco: a citaçãorelíquia, cuja função é a de autentificar o discurso citante; a citação-epígrafe, que contribui na inserção de um texto em um conjunto maior de obras; a citaçãocultura, próxima à citação-relíquia, tem urna função fática predominante, pois se constitui de um número indeterminado de enunciados famosos; e a citação-prova, 
usada para confirmar ou refutar um argumento, muitas vezes funciona também como citação de autoridade, isto é, é seu autor que confere valor ao conteúdo apresentado.

Analogamente ao princípio de que não se diz qualquer coisa de qualquer lugar - ponto chave da noção de formação discursiva - não se cita qualquer enunciado em qualquer texto. Até mesmo a localização da citação depende do tipo de relação entre as formações discursivas presentes no texto, isto é, entre a formação discursiva dominante e as demais colocadas em evidência. "O sujeito que enuncia a partir de um lugar definido não cita quem deseja, como deseja, em função de seus objetivos conscientes, do público visado, etc. São as imposições ligadas a este lugar discursivo que regulam a citação." (MAINGUENEAU, 1989, p.85). Citar é fazer entrar outros sentidos — mas não quaisquer sentidos — dentro de uma formação discursiva; é submeter tais sentidos a uma interpretação, de acordo com as regras do discurso citante.

Intertexto e intertextualidade são conceitos que contribuem na compreensão deste tipo de heterogeneidade. Por intertexto entende-se os fragmentos de fato citados por uma formação discursiva, já intertextualidade designa os tipos de citação que esta formação discursiva aceita. As citações, portanto, têm diferentes funções, circulam entre as formações discursivas de maneiras diferentes e podem ou não conferir legitimidade ao discurso citante.

Os textos de Cunha são formalmente enunciados enquanto discurso acadêmico, sofrendo, por motivos óbvios, a ingerência das formas de dizer consideradas legítimas pela academia. A citação de Pombal, bem como as outras existentes, enquadra-se no modelo institucionalizado: as fontes são apresentadas como legítimas, garantindo a imagem de seriedade dos trabalhos. Uma questão se coloca: seria possível filiar os textos de Cunha em alguma formação discursiva? Ou melhor, em se tratando dos sentidos que, desde o século XIX, vêm sendo produzidos sobre a língua falada no Brasil, como situar os textos em questão?

\section{CONDIÇÕES PARA EMERGÊNCIA DA CITAÇÃO}

Em primeiro lugar, faz-se necessário lembrar que para a análise do discurso os sentidos não têm uma origem determinada, nem são totalmente controlados. Reconhece-se, no entanto, nas formações discursivas, a matriz da constituição de sentidos. Nem falsos nem verdadeiros, trata-se apenas de sentidos em relações de forças numa época dada. Sentidos dominantes aparecem como evidentes, transparentes e únicos, parecem até familiares, e isso é resultado da predominância de uma formação discursiva sobre as demais. Por isso que na análise do discurso se fala em efeitos de sentidos e na ilusão da transparência da linguagem.

Ainda sobre as formações discursivas, deve-se acrescentar que elas têm como características a instabilidade e a reconfiguração incessante de suas 
fronteiras, características decorrentes das relações de forças, das disputas pelos sentidos dos diferentes períodos históricos. Tão importante quanto caracterizar as formações discursivas de uma época é depreender as relações estabelecidas entre elas tanto num plano sincrônico, quanto em termos diacrônicos, pois é em função dessas relações que elas vão reconfigurando suas fronteiras e os sentidos. As formações discursivas podem, então, "incorporar elementos pré-construídos produzidos no exterior delas mesmas (PÊCHEUX, 1988, p.161) como parte desse processo de redefinições, retornos, etc.

Como disse anteriormente, há uma disputa pelo sentido da língua falada no Brasil. Vários estudos vêm sendo realizados na tentativa de observar e analisar a historicidade desta questão. Mariani e Souza (1991), por exemplo, ao mapear este tema no século XIX, depreenderam três formações discursivas que, polemicamente, se confrontavam em torno de um imaginário de língua. Encontravam-se em disputa a formação discursiva dos românticos (que tinha em José de Alencar sua expressão maior, com o pleito, inclusive, do uso da denominação língua brasileira), a formação discursiva dos gramáticos (como J. Carneiro Ribeiro, F. J. Freire e A. Gomes, que, em suas gramáticas tanto incluíam listas de vocábulos indígenas e africanos falados no Brasil nas rubricas provincialismos ou brasileirismos, quanto peculiaridades do falar brasileiro como a colocação de pronomes) e a da lei (marcada pelas discussões da Assembléia Constituinte de 1823). No saldo da polêmica travada no século XIX, constata-se a vitória da formação discursiva dos gramáticos. Numa perspectiva purística, eles queriam preservar o bom português e este era o dos escritores de boa nota do século XVI. Do século XIX aos dias de hoje, ainda é possível detectar o predomínio da formação discursiva dos gramáticos, sobretudo no que se refere ao ensino. Isto não significa, porém, que a polêmica tenha deixado de existir. Ao contrário, além daqueles sentidos resistirem, novas questões foram formuladas, dando margem à produção de novos sentidos.

Nos textos de Cunha há várias pistas indicando um posicionamento contrário ao dos gramáticos tanto no que se refere à situação atual da língua falada no Brasil, e aos argumentos usualmente arrolados para justificá-la, quanto às políticas pedagógicas decorrentes da posição dos gramáticos.

Em Linguagem e condição social no Brasil, por exemplo, encontra-se um estudo quase totalmente voltado para a descrição das questões históricas que, do seu ponto de vista, foram determinantes em termos "do domínio do território e da expansão da língua portuguesa na América" (1979, p.57). Cunha, neste trabalho, afirma:

[...] nossos lingüistas não costumam levar em linha de conta as advertências dos historiadores quanto às peculiaridades da colonização lusa, quanto ao longo predomínio do meio rural sobre o urbano e, principalmente, quanto às características dos aglomerados humanos que se constituíram durante o período colonial, características que eles ainda vão conservar decênios decorridos da independência política. [...] Acresce salientar que essas cidades e vilas do período colonial, em verdade aldeias de crescimento desordenado, não podiam desempenhar o 
papel que lhes costumam atribuir nossos lingüistas, por motivos de ordem geográfica, demográfica e, principalmente, funcional, proibidas que foram de exercer atividades típicas de um centro urbano.

(id., p.57 e 59). estranha

Da mesma forma, em A questão da norma culta brasileira, Cunha

que certos lingüistas brasileiros fundem suas conclusões sobre a nossa modalidade idiomática partindo exatamente de uma influência normativa das cidades e vilas desde os primeiros tempos, cidades e vilas que conviveram sempre com a angustiante carência de escolas de nível primário e médio, que não tiveram universidades e que só começaram a conhecer a imprensa depois de 1801 .

(CUNHA, 1985, p.18).

Os dados históricos, comprovados através da citação de documentos variados, levam-no, por fim, a concluir:

O Brasil, o verdadeiro Brasil, não estava nas cidades. Estava então, como esteve, sem dúvida, até meados do século XIX, no campo, na zona rural. [...] Este antiurbanismo do brasileiro, tão olvidado nos estudos de nossos lingüistas, tem sido até elevado a princípio de comportamento humano, a uma filosofia de vida, por eminentes historiadores e sociólogos. [...] Nessa sociedade rural não podia vigorar uma norma lingüística fechada, nem haver um movimento literário de importância, o que exige vida urbana intensa. [...] até meados do século XIX, houve uma supremacia esmagadora do meio rural sobre o meio urbano, no qual influía de várias formas, inclusive modelando-lhe comportamentos lingüísticos.

(CUNHA, 1979a, p.63, 65 e 67).

Este raciocínio, pautado nas ponderações feitas por antropólogos, sociólogos e historiadores, somado à citação de inúmeros documentos (como, por exemplo, cartas e relatos de Teodoro Sampaio, do Padre Antonio Vieira e de Artur de Sá de Menezes, governador da Repartição Sul) que atestam o uso intenso da língua geral, permite a afirmação: "ainda no século XVIII, em certas partes do Brasil, a língua geral dominava a portuguesa [...]" (id., 1979a, p.72). Permite, assim, o afastamento enunciativo - justificado, legitimado - daquela formação discursiva que denominamos formação discursiva dos gramáticos.

"Nossos lingüistas não costumam [...]" e "certos lingüistas fundem [...]" são expressões que remetem para um campo de sentidos conhecido, isto é, aquele da formação discursiva dos gramáticos, incluindo, dessa forma, o próprio autor, mas, simultaneamente, remetem também para uma auto-exclusão dessa mesma formação discursiva. Há um estabelecimento de fronteiras entre o discurso do autor e o lugar a ele destinado pela formação discursiva. Tanto é assim que o intertexto que vem a seguir, conforme o próprio autor chama a atenção, é diferente daquele usualmente citado pela formação discursiva dos gramáticos.

Duas, pelo menos, são as possibilidades de análise: por um lado, é possível dizer que estaria se instaurando um lugar discursivo outro, diferente da 
tradição predominante ${ }^{3}$, i.e., resistente aos sentidos até então produzidos em torno do imaginário de língua; por outro lado, dado o fato de que as formações discursivas estão em um processo de incessante reconfiguração, talvez também seja possível dizer que a entrada de um intertexto novo não esteja produzindo diferenças suficientemente fortes, assim sendo, teríamos os mesmos sentidos, só que repetidos de modo diferente.

Vale a pena mencionar que a posição contrária à dos gramáticos se estende à discussão sobre posições político-pedagógicas. É o que se pode observar quando se lê:

Infelizmente, certos gramáticos nossos e grande parte dos professores da língua, esquecidos de que esta variabilidade posicional, [referência aos conceitos de Stepanov] por ser em tudo legítima, representa uma inestimável riqueza idiomática, preconizam, no particular, a obediência cega às atuais normas portuguesas, sendo mesmo inflexíveis no exigirem o cumprimento de algumas delas, que violentam duramente a realidade lingüística brasileira e que só podem ser seguidas na língua escrita, ou numa elocução altamente formalizada.

(CUNHA, 1981, p.18).

\section{A CITAÇÃO DO ÉDITO}

O diretório de Pombal, citado em função de seu papel histórico, funciona nos textos como uma citação-prova, isto é, como um suporte ou evidência favorável à argumentação desenvolvida. É dado ao fragmento um estatuto de documento histórico que comprova um fato, qual seja, o da ascensão da língua portuguesa com a conseqüente decadência da língua geral.

No artigo Linguagem e condição social no Brasil, o édito é introduzido por intermédio de uma forma metaenunciativa (AUTHIER-REVUZ, 1987). Solicitando permissão para dizer/citar o que foi efetivamente dito/citado, e concedendo a si mesmo esta permissão, o autor escreve: "[...] permitimo-nos citar, em abono de nossa tese, este passo esclarecedor do memorável documento pombalino inexplorado até agora por nossos filólogos [...]" (CUNHA, 1979a, p.72). Se há, no próprio artigo (e também nos outros) uma argumentação em curso na direção de questionar o status quo das discussões sobre a língua falada no Brasil, e, se o édito de Pombal tem a função de citação-prova (cf. "em abono de nossa tese [...]") qual a função de uma modalização por intermédio de uma representação metaenunciativa?

O diretório, como já mencionei anteriormente, é um fragmento estranho ao corpo do texto, ainda inexplorado, nos dizeres de Cunha, sobretudo por aqueles que compartilham sua própria área de conhecimento. O diretório constitui um intertexto não previsto, atuando na instabilidade da formação discursiva dos (nossos)

\footnotetext{
${ }^{3}$ Há, sem dúvida, outros textos de outros autores, que caminham na mesma direção de Cunha. Posso citar como exemplo o livro A língua portuguesa e a unidade do Brasil, de Barbosa Lima Sobrinho. 
gramáticos. E é no interior da própria formação discursiva, jogando com a heterogeneidade, que os sentidos vão se desestabilizando. Encontram-se, aqui, mais uma vez, fronteiras instauradas e uma tentativa de dar visibilidade às diferenças existentes.

Os comentários que seguem à citação vão ainda mais na direção de acentuar a influência do édito, justificando, assim, sua incorporação ao novo intertexto que está sendo produzido. Veja-se: 1) "A Reforma Pombalina [...] tornou violentamente obrigatório o ensino da língua portuguesa destruindo línguas e culturas indígenas [...] (1985, p.80); 2) "De que essas medidas tiveram um resultado prático não pode restar dúvida. As objeções que lhe quiseram opor, ao tempo, os defensores do bilingüismo não tiveram força para impedir que a $12 \mathrm{de}$ maio de 1798, quando o Diretório foi abolido por recomendação de D. Francisco Maurício de Souza Coutinho, Governador do Pará, a língua portuguesa não mais precisasse ser imposta para dominar inconcussamente, com exceção da Amazônia, as próprias regiões brasileiras quarenta anos antes de predominante influência Tupi." (1985, p.80 e 1979a, p.73); 3) "[...] vamos encontrar claramente expressa na criação dos Diretórios pelo Marquês de Pombal, golpe de morte dado na "língua geral' em nosso país." (1979b, p.85).

Em seu conjunto, as expressões valorativas utilizadas - "[...] tornou violentamente obrigatório [...]", "língua portuguesa não mais precisasse ser imposta [...]", "[...] golpe de morte [...]" - resultam do gesto interpretativo do colocar a citação no texto. Cunha previamente já havia dito que "a decadência vertiginosa no falar indígena" teve como "fator decisivo a expulsão dos jesuítas e as medidas tomadas pelo Diretório de 3 de maio de 1757 [...] que tornaram obrigatório o uso oficial da língua portuguesa." (1979a, p.72). Ao édito de Pombal, por seu poder coercitivo, é atribuída a responsabilidade pela alteração crucial da língua dominante no Brasil até o século XVIII. A partir da citação, portanto, toma-se possível ressignificar a oposição língua geral versus língua portuguesa até então pouco explorada ou pouco compreendida, mas não totalmente desconhecida.

Após a citação e após os comentários, aparecem mais uma vez as diferenças em termos de posições enunciativas, porém, mais abrandadas, evidenciando uma adesão parcial aos sentidos dominantes. Veja-se:

Em resumo: o jesuíta e o bandeirante, que tanto se empenharam em submeter o índio, impondo-lhe a sua disciplina, se bem que antagonistas, eram sustentáculos ambos da língua geral. Daí admitirmos a premissa anti-substratista de Mattoso Câmara Júnior, de que a nação brasileira não ë um conjunto de tribos indígenas ou africanas que tenham adotado a língua portuguesa, sem que nos vejamos obrigados a chegar à conclusão do ilustre lingüista de que índios e negros estiveram sempre enquadrados numa grande massa branca e mestiça luso-falante. (1979a, p.74).

Em outro artigo, pode-se depreender a diferença representada como necessidade de reconfiguração da formação discursiva:

Qualquer periodização que se proponha para a história da língua portuguesa, principalmente para a da variante brasileira, não pode, pois, deixar de considerar um marco fundamental, o nascimento de uma nova 
era no ensino normativo do idioma, as medidas tomadas pelo marquês de Pombal [...] (1985, p.81).

Pode-se dizer, então, que os textos de Cunha apontam na direção do rompimento com uma memória discursiva sobre as relações de força entre o português e a língua geral. Ao trazer novos sentidos, Cunha dimensiona o édito de Pombal enquanto discurso fundador, ou seja, enquanto "referência básica no imaginário constitutivo desse país" (ORLANDI, 1993, p.7) a respeito da língua. A referência ao édito, no entanto, não rompe totalmente com uma memória da supremacia da língua portuguesa.

A questão que havia sido formulada anteriormente pode ter, agora, uma resposta: as diferenças postuladas apontam mais para uma rearrumação das fronteiras da formação discursiva dos gramáticos do que para o surgimento de uma nova. As divergências sugerem mais a necessidade da incorporação de fato da questão da língua geral nas discussões sobre o imaginário de língua e de norma culta travadas por gramáticos, filólogos e lingüistas. E por quê? São outras as relações de força em jogo atualmente. O português do Brasil, nos dias de hoje, não pode mais ficar restrito à rubrica provincialismos. Os laços de dependência mudaram em termos históricos, mas ainda não se extinguiram totalmente, daí a reorganização das fronteiras da formação discursiva, mas não o seu apagamento, mas não uma ruptura.

\section{REFLEXÕES FINAIS}

Do ponto de vista discursivo, um outro aspecto pode ser enfocado: as rubricas provincialismos e brasileirismos evidenciam, no século XIX, a existência de uma prática de linguagem que não se confunde nem com a língua geral, nem com a língua portuguesa imposta. Seria lícito, então, supor que as gramáticas do século XIX citam formas de dizer que já circulavam no século anterior e que não eram específicas de línguas indígenas ou africanas. Citam estas formas enquanto desvio do bom português de Portugal, formas que, em sua maioria, não tinham registro escrito a não ser nos textos literários de alguns escritores do romantismo. Diz Orlandi:

[...] o português do Brasil e o português de Portugal já significam diferentemente, mesmo que não se o reconheça. Antes de tudo, para entender esse processo significante é preciso entender que há um jogo em relação aos países colonizados em geral - que poderíamos chamar de heterogeneidade lingüística [...]. Heterogeneidade lingüística, no sentido de que joga no caso da nossa língua, um fundo falso em que o mesmo abriga no entanto um outro, um diferente que o constitui na aparência da mesmidade: o português brasileiro e o português de Portugal se recobrem como se fossem a mesma língua. E não são. Discursivamente é possível vislumbrar esse jogo de prestidigitação pelo qual no mesmo lugar há uma presença dupla, de pelo menos dois discursos distintos, efeitos de uma clivagem de duas histórias na relação 
com a língua portuguesa: a de Portugal e a do Brasil. Nós, brasileiros, ao falarmos o português estamos sempre nesse ponto de disjunção obrigada. A nossa língua significa em uma filiação de memória heterogênea. São duas formações discursivas como se fossem uma só. (1993, p.22).

Nesse sentido, o édito de Pombal, no século XVIII, estaria atuando no confronto entre esse falar brasileiro, ainda totalmente restrito à oralidade, à língua geral e às diversas línguas indígenas existentes e ao português do príncipe. Legitima-se, através da imposição do édito, o português de Portugal nas instituições escolares e religiosas, legitimando-se, também, o apagamento da língua geral e das línguas indígenas.

Mas há uma complexidade que vai além da preconizada por Cunha: não se trata apenas de um Brasil rural opondo-se a um Brasil incipientemente urbano. Ponto não mencionado pelo autor, mas igualmente relevante quando se estuda a questão da linguagem no século XVIII, é a existência das muitas academias literárias que promoviam eventos variados e também se dedicavam a fazer pesquisas em botânica e em história. Tais academias, cujo papel na normatização do português no Brasil merece maior atenção (cf. MARIANI, 1991), sem dúvida aparecem como um contraponto à língua geral e ao Brasil rural enfatizado por Cunha. Da mesma maneira, os cinquienta anos de duração do diretório de Pombal também devem ser investigados profundamente.

\section{ANEXOS}

1) O édito de Pombal conforme citado no texto Linguagem e condição social no Brasil:

sempre foi máxima inalteravelmente praticada em todas as nações que conquistaram novos domínios, introduzir logo nos povos conquistados o seu próprio idioma, por ser indispensável, que este é um meio dos mais eficazes para desterrar dos povos rústicos a barbaridade dos seus antigos costumes e ter mostrado a experiência, que ao mesmo passo que se introduz neles o uso da língua do Príncipe, que os conquistou, se lhes radica também o afeto, a veneração e a obediência ao mesmo Príncipe. Observando pois todas as Nações polidas do Mundo este prudente e sólido sistema, nesta conquista se praticou pelo contrário, que só cuidavam os primeiros conquistadores estabelecer nela o uso da Língua, que chamamos geral, invenção verdadeiramente abominável e diabólica, para que privados os índios de todos aqueles meios que os podiam civilizar, permanecessem na rústica e bárbara sujeição, em que até agora se conservam. Para desterrar este perniciosíssimo abuso será um dos principais cuidados Diretores estabelecer nas suas respectivas povoações o uso da língua portuguesa, não consentindo por modo algum que os Meninos e Meninas, que pertencerem às escolas, e todos aqueles índios que forem capazes de instrução nesta matéria, usem da língua própria 
das suas nações ou da chamada geral, mas unicamente da Portuguesa, na forma que S. M. tem recomendado em repetidas ordens, que até agora não se observaram, com total ruína espiritual e temporal do Estado.

(CUNHA, 1975, p.72-73).

2) $\mathrm{O}$ édito de Pombal conforme citado no texto A situação lingüística de Cabo Verde e Guiné-Bissau: português e crioulo frente a frente:

sempre foi máxima inalteravelmente praticada em todas as nações, que conquistaram novos domínios, introduzir logo nos povos conquistados o seu próprio idioma, por ser indispensável, que este é um dos meios mais eficazes para desterrar dos povos rústicos a barbaridade dos seus antigos costumes e ter mostrado a experiência, que ao mesmo passo que se introduz neles o uso da língua do Príncipe, que os conquistou, se lhes radica também o afeto, a veneração e a obediência ao mesmo Príncipe. Observando pois todas as Nações polidas do Mundo este prudente e sólido sistema, nesta conquista se praticou pelo contrário, que só cuidavam os primeiros conquistadores estabelecer nela o uso da língua, que chamaram geral; invenção verdadeiramente abominável e diabólica, para que privados os índios de todos aqueles meios, que os podiam civilizar, permanecessem na rústica e bárbara sujeição, em que até agora se conservam. Para desterrar este perniciosíssimo abuso será um dos principais cuidados dos Diretores estabelecer nas suas respectivas povoações o uso da língua portuguesa, não consentindo por que os Meninos e Meninas, que pertencerem às escolas, e todos aqueles índios que forem capazes de instrução nesta matéria, usem da língua própria das suas nações ou da chamada geral, mas unicamente da Portuguesa, na forma que S. M. tem recomendado em repetidas ordens, que até agora não se observaram, com total ruína espiritual e temporal do Estado.

(publicado na revista Studia, 9, 1979, p.39-53, e em Língua, nação, alienação, 1981).

3) O édito de Pombal conforme citado em A questão da norma culta brasileira:

sempre foi máxima inalteravelmente praticada em todas as nações que conquistaram novos domínios, introduzir logo nos povos conquistados o seu próprio idioma, por ser indispensável, que este é um meio dos mais eficazes para desterrar dos povos rústicos a barbaridade dos seus antigos costumes e ter mostrado a experiência que, ao mesmo passo que se introduz neles o uso da língua do Príncipe, que os conquistou, se lhes radica também o afeto, a veneração e a obediência ao mesmo Príncipe. Observando pois todas as Nações polidas do Mundo este prudente e sólido sistema, nesta conquista se praticou pelo contrário, que só cuidavam os primeiros conquistadores estabelecer nela o uso da língua, que chamamos geral, invenção verdadeiramente abominável e diabólica, para que privados os índios de todos aqueles meios que os podiam civilizar, permanecessem na rústica e bárbara sujeição, em que até agora se conservam. Para desterrar este perniciosíssimo abuso será um dos principais cuidados dos Diretores estabelecer nas suas respectivas povoações o uso da língua portuguesa, não consentindo por modo algum que os Meninos e Meninas, que pertencerem às escolas, e todos aqueles índios, que forem capazes de instrução nesta matéria, usem da língua 
própria das suas nações ou da chamada geral, mas unicamente da Portuguesa, na forma que S. M. tem recomendado em repetidas ordens, que até agora não se observaram, com total ruína espiritual e temporal do Estado

\section{BIBLIOGRAFIA}

(CUNHA, 1985, p.79-80).

AUTHIER-REVUZ, Jacqueline. L'auto-répresentation opacifiante du dire dans certaines formes de "couplage". DRLAV, n.36-37, p.55-103.

CUNHA, Celso. Linguagem e condição social no Brasil. Revista de Letras, Fortaleza, v.2, n.1, p.55-78, jan./jun. 1979.

A situação lingüística de Cabo Verde e Guiné-Bissau: português e crioulo frente a frente. In: Língua, nação alienação. Rio de Janeiro, Nova Fronteira, 1981.

. A questão da norma culta brasileira. Rio de janeiro, Tempo Brasileiro, 1985.

MAINGUENEAU Dominique. Novas tendências em Análise do Discurso. Campinas, Pontes/UNICAMP, 1989.

MARIANI, Bethania S. C.; SOUZA, Tania C. 1822, pátria independente: outras palavras? Organon, Porto Alegre, v.8, n.21, 1994.

MARIANI, Bethania S. C. As academias do século XVIII - um certo discurso sobre a história e sobre a língua do Brasil. In: ENCONTRO NACIONAL DA ANPOLL. Anais do $8^{o}$ Encontro Nacional da ANPOLL. Porto Alegre, ANPOLL, 1992.

ORLANDI, Eni P. Discurso e Leitura. Campinas, Cortez/UNICAMP, 1988. . Vão surgindo sentidos. In: ORLANDI, Eni P. (org). Discurso fundador; a formação do país e a construção da identidade nacional. Campinas, Pontes, 1993.

PÊCHEUX, Michel. Semântica e discurso; uma crítica à afirmação do óbvio. Campinas, Ed. da UNICAMP, 1988.

. O discurso: estrutura ou acontecimento. Campinas, Pontes, 1990. 
